\title{
Escudos y marcas tipográficas de editoriales científicas del siglo XX
}

José Antonio Rodríguez Valcárcel *

Artículo recibido:

10 de enero de 2005.

Artículo aceptado:

2 de mayo de 2005.
RESUMEN:

Este artículo se propone recopilar algunas de las marcas tipográficas utilizadas por editoriales científicas del siglo XX para mostrar su riqueza y variedad. Se comienza por reseñar el origen renacentista de dichas marcas, sus tipos y simbolismos, para luego continuar con el esbozo histórico de alguna de las marcas o logotipos comerciales actuales recogidos, en paralelo con la propia historia de la empresa, y que pertenecen a algunas de las más prestigiosas editoriales científicas que han llegado hasta nuestros días.

Palabras clave: marcas tipográficas, divisas, editoriales, siglo XX.

* Consejo Superior de Investigaciones Cientificas (CSIC), España. xjoseanx@hotmail.com INVESTIGACIÓN BIBLIOTECOLÓGICA, Vol. 20, Núm. 40, enero/junio, 2006, México, ISSN: 0187-358X. pp. 32-52 
ABSTRACT

Emblems and typographical imprints of XXth century scientific publishers

José Antonio Rodríguez-Valcárcel

This article brings together a collection of typographical imprints used by scientific publishers of the XX century in order to show their richness and variety. The origin, types and symbolism of such imprints are traced back to the Renaissance period, and the historical outline of some of these imprints or commercial logotypes of the most prestigious scientific editors of today, is revealed together with the history of these enterprises.

Keywords: Imprints; Emblems; Publishers, XXth century.

\section{INTRODUCCIÓN}

U na de las características del siglo XX, desde un punto de vista editorial, ha sido la "explosión informativa", hecho que ha llevado las cifras de edición hasta cotas nunca alcanzadas con anterioridad. En lo que a la edición científica se refiere, este aumento es producto, en primer lugar, del incremento del número de científicos, traducción a su vez de las mejoras de los sistemas educativos, y de la existencia de un mayor número de canales para la difusión de la investigación, siempre teniendo en cuenta que se trata de un fenómeno que afecta a unos pocos países en los que se concentra la práctica totalidad de la edición científica, a saber: Estados Unidos, Holanda, Alemania y el Reino Unido.

Por otro lado, una segunda característica de ésta, así denominada "explosión" documental, debe hallarse en la mayor compartimentación y especialización de las ciencias. ${ }^{1}$ Si en el siglo XIX, la mayor parte de la edición se concentraba en las ciencias físicas, en el XX dicha especialización ha provocado también la diversificación de la edición.

Un tercer factor que ha contribuido al fenómeno ha sido la transformación de las instituciones científicas para acomodarse a la realidad anterior y al incremento constante, por ejemplo, del número de departamentos universita-

1 A. J. Meadows, "Science Publishing in the twentieth Century", en Thorton and Tully's Scientific Books, Libraries and Collectors. Aldershot, 2000. pp. 272-297. 
rios desde la Segunda Guerra Mundial. Los editores comerciales vieron en ello una gran oportunidad para publicar libros y revistas científicas, como el caso de Pergamon Press, algunas de ellas mediante contratos de colaboración entre sociedades científicas universitarias y las editoriales. Otras, que ya funcionaban con anterioridad al periodo que estamos tratando, se decantaron por esta vía de negocio, otras más lo hicieron parcialmente por medio de ramas o divisiones paralelas especializadas y muchas otras más nacieron ya con una vocación de editoriales científicas, todo lo cual contribuyó a aumentar su número, como podrá verse en la disparidad de marcas o escudos tipográficos que se presentan.

Estas marcas comerciales parecen haberse originado al mismo tiempo que la invención de la propia imprenta ya que fueron precisamente los continuadores de la obra de Gutenberg, Fust y Schoeffer, los primeros impresores que utilizaron estos "logotipos", por llamarlos de esta manera aunque se trate de un término extemporáneo. Muchas de estas marcas fueron muy difundidas a lo largo del tiempo como el áncora y el delfín de Manucio, empleada incluso en épocas recientes, o han sido reutilizadas constantemente, como la marca de la imprenta de Juan de la Cuesta, donde vio la luz la narración de las aventuras del más insigne caballero de todos los tiempos: El ingenioso hidalgo Don Quijote de la Mancha (Fig. 1). Representa un halcón sostenido por un

\section{EL I NGE N IOSO HIDALGO DON QVI. XOTE DE LA MANCHA, Compuefto por Miguel de Ceruantes Saanedra.}

DIRIGIDOAL DVQVE DE BEIAR, Marques de Gibraleon, Conde de Benalcaçar, y Bañares, Vizconde de la Puebla de Alcozer, Señor de las villas de Capilla, Curiel, y Burguillos.

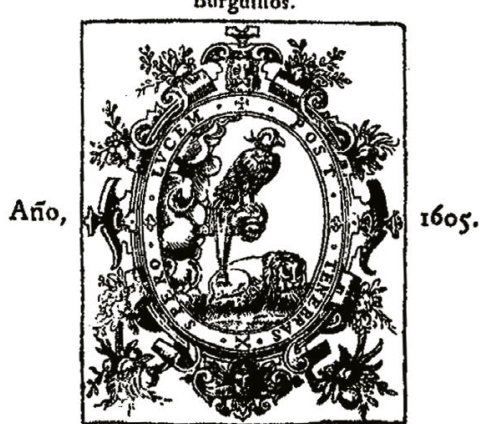

CON PRIVILEGIO, $E N x_{A D} D D$, Por luan de la Cuefta.

vendefe en esfade Prancifico de Robbles, librero del Rey abónobiose 
puño enguantado y rodeado por la leyenda Post tenebras spero lucem. Este emblema no era original de este impresor ya que había sido utilizado por el anterior posesor de ese taller, Pedro Madrigal, quien ejerció su actividad en la segunda mitad del siglo XVI. ${ }^{2}$ La marca, sin embargo, parece mucho más antigua y estar geográficamente bastante difundida, como lo prueba su existencia en Medina del Campo a mediados de dicho siglo bajo la marca del taller de Millis ${ }^{3}$ y por Juan Mommarte en Bruselas en 1604, entre otros. Este hecho hace pensar en un simbolismo que aludiría al gremio de los impresores y de ahí su reutilización, la cual está relacionada con la idea de llevar los impresos a muchos lugares y dispersar la ignorancia.

La marca de Fust y Schoeffer fue utilizada en una Biblia de 1462 y estaba constituida por un tronco o una rama de la que pendían dos escudos con las armas de cada uno de los dos impresores. Los dos brotes de la rama representan a los tipógrafos (Fig. 2), ${ }^{4}$ al igual que en otras marcas menos elaboradas y que consistían en dibujos geométricos de círculos y rayas, en los que sobre dos círculos concéntricos se superponían rayas verticales y horizontales, cuyo número, con frecuencia, hacía alusión al número de integrantes del taller de impresión (Fig. 3).
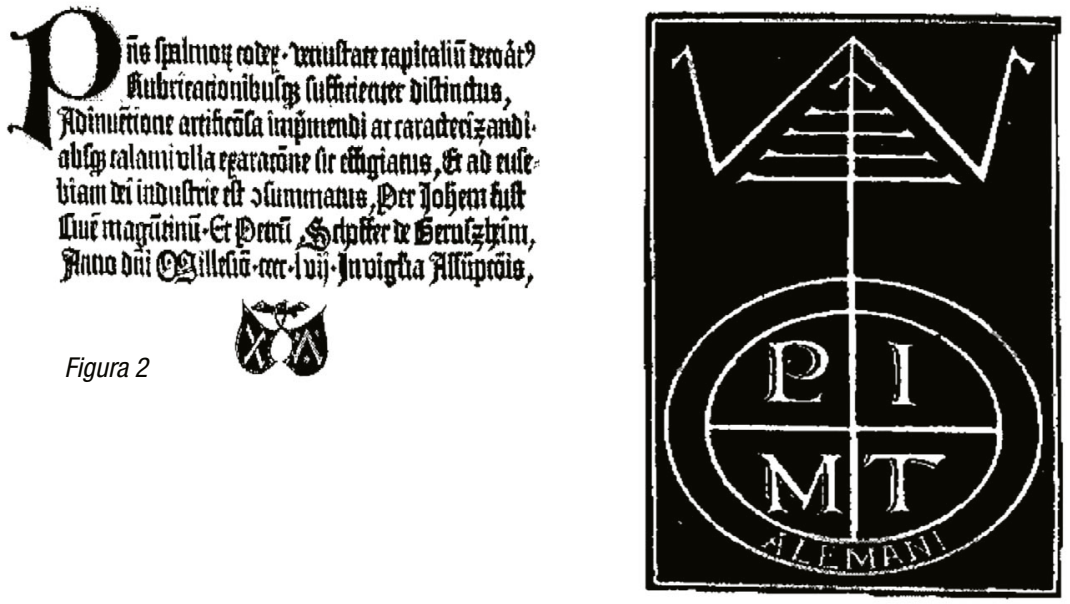

Figura 3

2 Juan de la Cuesta después de trabajar en Segovia, donde se había instalado en 1588, se trasladó a Madrid hacia finales del siglo, donde pasó a trabajar en el taller de Madrigal. Vid. Pérez Pastor, C., Bibliografía madrileña o descripción de las obras impresas en Madrid, Madrid, 18911907

3 La imprenta en Medina del Campo, Madrid: Sucs. De Rivadeneyra, 1895. Ed. Facsímil: Salamanca, Junta de Castilla y León, 1992

4 F. Vindel, Escudos y marcas de impresores y libreros en España durante los siglos XV a XIX (14851800), Barcelona: Orbis, 1942. 
Generalmente esta marca se colocaba tras el colofón en la última página, a no ser que por falta de espacio se trasladara a la portada. La razón de su incorporación a los libros quizá debemos verla relacionada con el nuevo signo de los tiempos renacentistas que despuntaban en ese entonces. El individuo se mostraba en su plenitud; los libros no eran ya copiados por monjes anónimos sino que eran impresos por gentes que estaban en el mundo (un mundo en el cual hacía falta sobrevivir) y se debían a su negocio. El orgullo profesional pero también comercial -disponer de un signo que los distinguiera de los demás- hizo el resto. Famosos impresores por la calidad de sus textos tuvieron su marca como Aldo Manucio (Fig. 4), la que fue copiada de una moneda de la época de Tiberio que representaba un áncora sobre la que se enroscaba un delfín y a ambos lados de ella el nombre ALDVS y una leyenda: FESTINA LENTE, o Cristóbal Plantino (Fig. 5). ${ }^{5}$

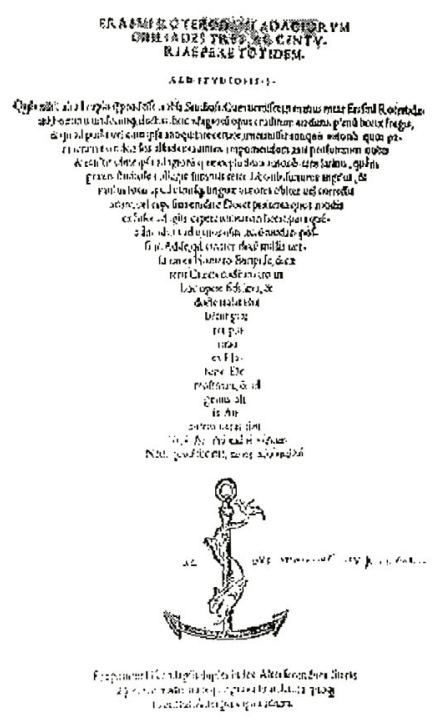

Figura 4

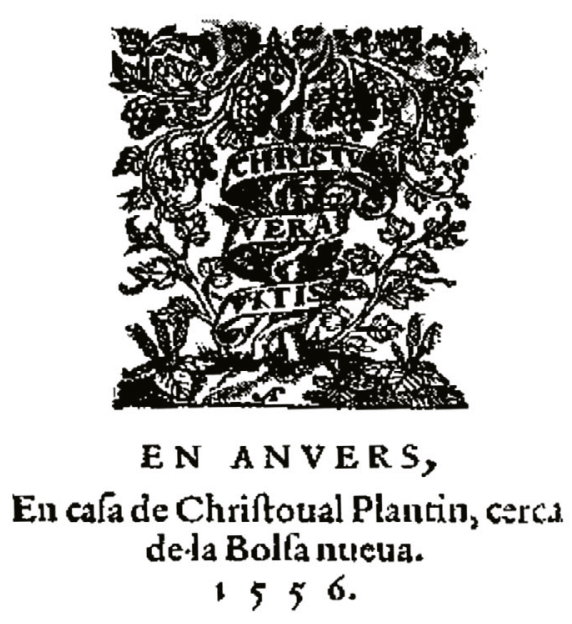

Figura 5

Tipos DE MARCAS

Vindel $^{6}$ estructura las marcas que recoge en su pionero estudio en cuatro categorías, desde los siglos XV a XIX: 
1) Marcas geométricas.

2) Marcas o escudos alegóricos o simbólicos.

3) Marcas o escudos con adornos tipográficos.

4) Marcas caligráficas.

1) Las marcas geométricas están formadas por un círculo o bien por dos círculos concéntricos sobre el o los que se encuentra una cruz; en otras ocasiones en lugar de un círculo se trata de un triángulo. Este tipo parece que fue perdiendo su individualidad para integrarse en otros de mayor elaboración, fuera ésta tipográfica o alegórica (fig. 6).

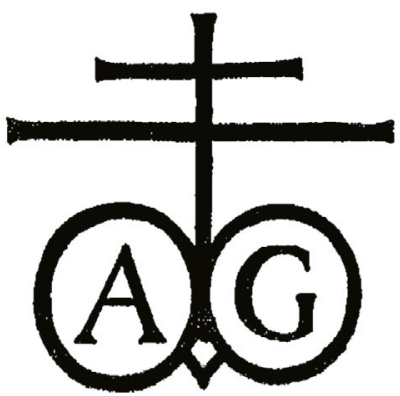

Figura 6

2) Las de carácter simbólico parecen contener elementos comunes al gremio de los impresores y libreros como los que integran figuras de aves: águilas, pelícanos, halcones, etcétera. Otro motivo más curioso aún es la representación de una mano o más en diversas actitudes o bien portando emblemas de distinto tipo. Interesantes son también las alegorías basadas en los apellidos de los impresores, como el de Pedro Lacavallería (Fig.7).

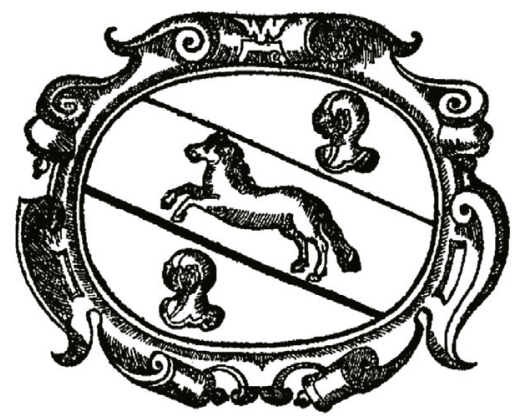

Figura 7 
3) La tercera categoría está constituida por los adornos tipográficos que no señalan o aluden a una persona, taller o motivo alguno.

4) Las marcas caligráficas realizan en ocasiones complicados diseños que utilizan el nombre del impresor o sus iniciales con rasgos caligráficos (Fig. 8).

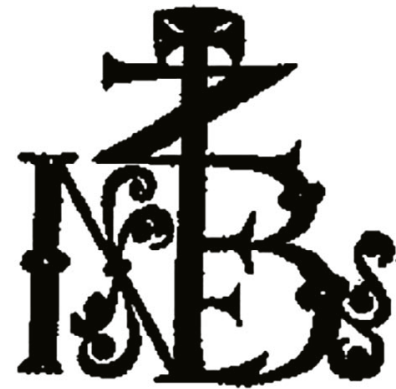

Figura 8

Este esquema será también válido, y abarcará un periodo que comprende desde el origen de las marcas hasta el siglo XIX, para clasificar nuestras marcas tipográficas del siglo XX, las cuales han sido seleccionadas sin ningún afán de exhaustividad y únicamente como excusa para realizar esta aproximación. Pero conozcamos algunas editoriales contemporáneas y sus "logotipos".

\section{EDITORIALES CIENTÍFICAS INTERNACIONALES DEL SIGLO XX}

Escogeremos algunas de las más reconocidas internacionalmente y de las cuales es posible conocer con exactitud su origen e historia y, con ella, la de su marca editorial.

\section{Springer}

La familia Springer llegó a Berlín desde Frankfurt on-Oder, y Julius Springer, el fundador, nació en aquella localidad el 10 de mayo de 1817. Fue también en este lugar donde comenzó a trabajar como aprendiz con Ferdinand Müller. Posteriormente vivió dos años en Zurich -de 1836 a 1838- y en la primavera de ese año se desplazó a Stuttgard como asistente de Paul Neff en la librería que éste poseía en aquella ciudad. La experiencia adquirida aquí le resultó muy útil para fundar más tarde su propio negocio. Llegó a París en 
1839 y comenzó a trabajar en la librería Brockhouse and Avenarius, y retornó a Berlín pocos meses después. En una carta del 14 de febrero de 1842 escribía sobre los planes de creación de su propia empresa y ese mismo año obtuvo el permiso para establecerse; a tal efecto, insertó un anuncio en la Gaceta del comercio alemán de libros el 6 de abril, donde se informaba de la apertura de la librería. Desde ese momento hasta la actualidad Springer Verlag se ha convertido en un gran grupo editorial presente en numerosos países de Europa y también en Estados Unidos y Japón.

Su marca editorial data del año 1881 y ha variado muy poco hasta la actualidad. El diseño se debe a Wilhem Martens sobre un borrador de Martin Gropius. En él las iniciales del fundador J y S, se hallan rodeadas por la leyenda de la empresa Alle zeit wach (o Kracht en una variación), formulada por Ferdinand Springer. La cabeza del caballo es una especie de juego entre el nombre alemán de la pieza del ajedrez y la afición, tanto de Julius como de sus dos hijos Ferdinand y Fritz, a dicho juego, como queda dicho (Figs. 9-12). Durante la Segunda Guerra Mundial, hubo que cambiar las iniciales del nombre del fundador - una J- por la V de la palabra alemana para editorial, debido a la arianización de las industrias alemanas que estaba llevando a cabo el partido nazi, ya que en este caso el nombre les parecía algo judío; lo cual era cierto debido a un ancestro aunque esta cuestión había sido cuidadosamente ocultada por Springer. El viejo logotipo fue de nuevo utilizado después de $1946 .^{7}$

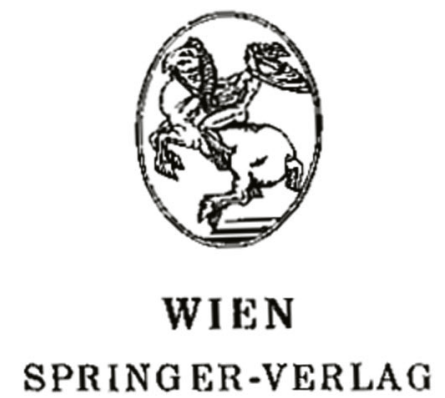

1949

Figura 9

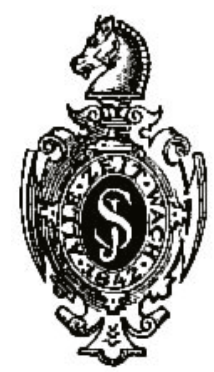

1881

Figura 10

7 Un nuevo logotipo fue diseñado en 1976 por el artista Max Bollwage, el cual fue usado especialmente en libros en lengua no alemana con fines comerciales. 


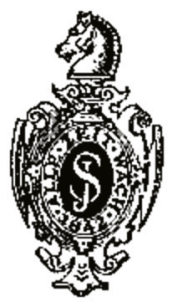

1941-1946

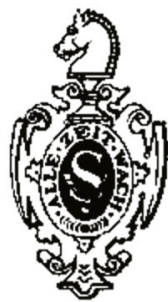

1970-1984

Figura 11

Figura 12

\section{Longman}

Cuando el primer Longman de nombre Thomas compró una librería y una imprenta en Londres en 1724, el símbolo que siempre estuvo colgado en su puerta fue el de un barco con todo su velamen desplegado (Fig. 13). El diseño era más antiguo, de cuando John Crook en 1640 estableció dicho negocio en el área de la catedral de San Pablo, pero el gran fuego de 1666 forzó a Crook al traslado a Ducklane, y Benjamin Tooke, sucesor de Crook, lo devolvió a su primitivo emplazamiento, y luego se lo vendió a John Taylor y éste a Longman. Tal tradición hizo escribir al primer ministro Disraeli en 1880 "I was glad to see the old ship again, and trust it may be auspiciuos of a good voyage!". 8

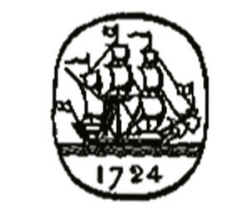

\section{LONGMANS}

Figura 13

\section{John Wiley and Sons}

Wiley data de 1807, cuando Charles Wiley abrió una imprenta en Maniatan y publicó en un principio a Washington Irving, Poe y Melville; pero fue en 
1848 cuando se especializó en publicaciones sobre ciencia y tecnología. Ya en el siglo XX, será en la década de los sesenta cuando comience su expansión hacia Europa, Australia y Asia, al ser jalonada su trayectoria por las continuas compras de diversas compañías como Van Nostrand Reinhold en 1977. Posee actualmente unas cuatrocientas revistas y publica unos dos mil títulos al año.

Su logo está formado por un círculo, algo achatado, que contiene las iniciales de John Wiley cruzadas en su centro (Fig. 14).

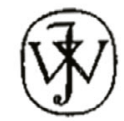

AN INTERSCIENCE ${ }^{\circledR}$ PUBLICATION

JOHN WILEY \& SONS, INC.

NEW YORK $\bullet$ CHICHESTER $\bullet$ BRISBANE $\bullet$ TORONTO $\bullet$ SINGAPORF:

Figura 14

\section{Wolters Kluwer}

Comenzó como negocio familiar en el siglo XIX, cuando J.B. Wolters, A. E. Kluwer y N. Samsom fundaron la empresa hacia 1889 en Holanda. Desde entonces, sobre todo desde fines de los años ochenta, ha integrado más de trescientas empresas editoriales de todos los tamaños como Silver Platter. La empresa se ha extendido por Europa y Norteamérica con publicaciones en las áreas de humanidades, ciencias sociales, ciencias físicas e ingenierías. Su portal on line, [www.kluweronline.com], contiene revistas, libros electrónicos y material de referencia.

El último "logo" perteneciente a la corporación data del año 2003 y representa un libro que simboliza la fuente del conocimiento. Sus páginas abiertas muestran la difusión de este conocimiento entre sus clientes (Fig. 15).

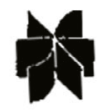

\section{KLUWER ACADEMIC PUBLISHERS \\ DORDRECHT / BOSTON / LONDON}

Figura 15

\section{Elsevier}

El nombre de la compañía está inspirado en la casa editorial que fue fundada en 1580 por Lowys Elsevier, quien ya imprimía y vendía libros a las universidades. 
Pero fue un librero holandés e importador de libros en lengua inglesa, Jacobus George Robbers, quien fundó la moderna Elsevier en 1880. Sus primeras publicaciones científicas datan ya de los años treinta del siglo XX y fueron traducciones de textos científicos alemanes. En los años cincuenta y sesenta inició su expansión internacional y, como todas las empresas, en las décadas posteriores ha llevado a cabo diversas operaciones comerciales como resultado de las cuales se ha convertido en propietaria de editoriales como North Holland Publishing o Pergamon Press.

El escudo de la editorial fue utilizado por primera vez por Isaac Elsevier en 1620 y muestra un olmo delante del cual permanece de pie un hombre. El árbol sustenta la leyenda NON SOLUS. De éste existe una variante en el que únicamente se mantiene la leyenda rodeando un escudo que contiene tres cruces en su interior (Figs. 16 y 18 respectivamente, aparte de otro más moderno en el que sólo se ponen las iniciales, Fig. 17).

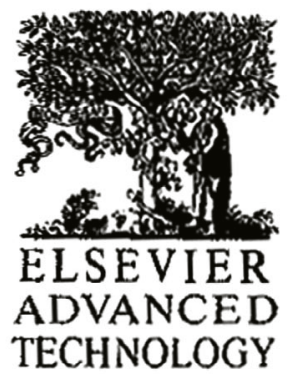

Figura 16

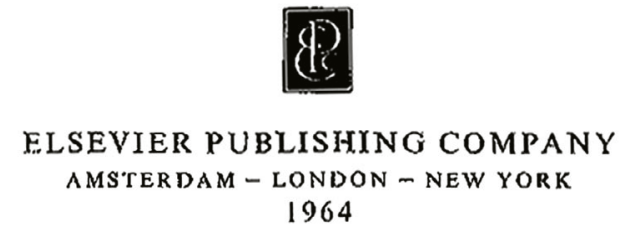

Figura 17

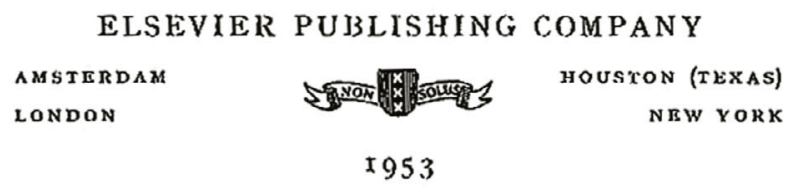

Figura 18

\section{Taylor and Francis Group}

Su fundador fue Richard Taylor, quien en 1798 lanzó el Philosopbical Magazine, una de las primeras revistas científicas editadas por una empresa independiente de las sociedades científicas de la época. En 1852 William Francis, químico, se unió a Taylor y modificó la compañía que en la actualidad ostenta su nombre y que se ha consolidado con la compra del grupo Routledge, y 
abierto oficinas en Londres, Brighthon, Estocolmo o Nueva York así como en La India. Publica unas setecientas revistas y alrededor de mil ochocientas monografías anuales.

Su logotipo es una lámpara de aceite encendida, lo cual podría simbolizar cómo el conocimiento disipa las tinieblas de la ignorancia (Fig. 19).

\section{Taylor \& Francis \\ Taylor \& Francis Group}

Figura 19

\section{Blackwell Publishing}

La actual Blackwell Publishing es el resultado de la fusión entre Blackwell Publishers y Blackwell Science en 2001. Blackwell Publishers publicó su primer libro en 1897, pero hasta la década de 1970, cuando se transformó en una reconocida editorial de libros académicos, había publicado las obras de Tolkien, Auden, Greene y Wittgenstein, y se convirtió en los años noventa en uno de los líderes en la publicación de revistas para grupos interesados en ciencias sociales y humanidades. La parte de ciencias Blackwell Science fue fundada por Sir Basil Blackwell en 1939 y denominada Blackwell Medical Publications y poco después Blackwell Scientific Publications. Comenzó en los años 50 con una lista de revistas a las que en los años sesenta añadió también monografías. Hoy es una gran compañía transnacional con oficinas en Europa, Estados Unidos, Australia y Japón.

Su logotipo es bastante sencillo, y está representado por la B de Blackwell en letra minúscula (Fig. 20).

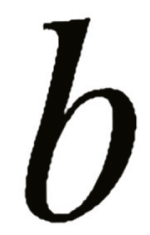

\section{Blackwell}

Science

Figura 20 


\section{Pergamon Press}

Ya desaparecida al ser integrada por el grupo Elsevier, había nacido en 1948 como una joint venture entre Springer y Butterworths para publicar monografías y revistas científicas. Fue comprada en 1951 por Robert Maxwell y finalmente, como hemos dicho, vendida a Elsevier.

Su logo está representado por una antigua moneda griega, en cuyo diseño moderno intervino el gran diseñador Heinz Götze (Fig. 21).

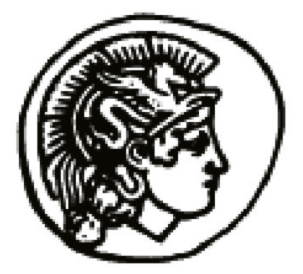

Figura 21

\section{Macmillan}

Fue fundada en 1843 por los hermanos escoceses Daniel y Alexander Macmillan, quienes publicaron en principio a autores como Kipling, Tennyson o Wells, y poco después a Keynes y Yeats. En 1869 crearon la revista Nature y el Grove Dictionnary of Music and Musicians en 1877, como productos señeros de aquellos años y que aún mantienen toda su vigencia. No fue sino hasta los años sesenta del siglo XX, coincidiendo con la presidencia de la empresa de Harold Macmillan, cuando se inició un ambicioso programa de expansión hacia Japón, México y África. En 1955 fue comprada en su mayoría por Verlagsgrouppe Georgs Von Holtzbrinck, compra que se remató en 1999. Fue así como desapareció una larga tradición editorial, que sin embargo mantuvo como uno de sus mayores activos al Nature Publishing Group (Fig. 22).

Este logo estaba basado exclusivamente en los apellidos del fundador de la empresa y se crearon diversas variaciones a lo largo del tiempo sobre estos mismos apellidos.

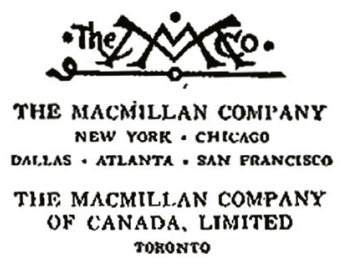

Figura 22 


\section{CONCLusiones}

Estas marcas, ya contemporáneas -siglo XX-, no aparecerán ya en el colofón, o por lo menos no exclusivamente, sino en la portada de la publicación, y no asimilada al librero o al impresor sino al editor o grupo empresarial editor del documento en cuestión. Dicha marca puede aparecer también -y en esto se diferencian de las antiguas- en el lomo de la encuadernación, en la cubierta o en la sobrecubierta si es una monografía, y en la cubierta, en la portadilla -cuando ésta existe-, y en la portada si se trata de una publicación seriada. Los temas reflejados en estas marcas han variado también desde la aparición de los primeros tipos en el siglo XV. Se dan casos en los que las editoriales han ido modernizando su "logotipo", aunque la base del mismo sea idéntico al primer diseño, como el de Kluwer (Fig. 15 citada en la pag. 41) o, mejor dicho, Wolters Kluwer (Fig. 23).

\section{แل\WoltersKluwer}

Figura 23

Otras, sin embargo, como Longman retienen su famoso barco con el velamen desplegado (Fig. 13 ya citada en la p. 40), o como hace también la casa Elsevier y su olmo tricentenario (Fig. 16 ya citada, en la pag. 42), ${ }^{9}$ marcas que han sido mantenidas desde el principio, como hemos visto al reseñar las trayectorias de algunas de estas casas editoriales. Las alegorías están mucho menos presentes -por lo menos en las marcas editoriales que se tratan de presentar-y no parecen plantearse demasiadas complejidades en cuanto a su significación, sino más bien tender hacia la simplificación e inmediato reconocimiento de la "empresa", lo cual quizá puede explicar la razón de que la mayoría de las marcas sean del tipo que Vindel denomina "marcas caligráficas", en las que la base está constituida por el nombre o por sus iniciales: Academic Press (Fig. 24),

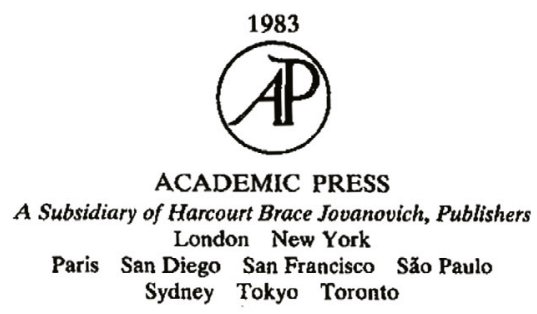

Figura 24 
Carl Hanser Verlag (Fig. 25 y 26), Hanser Publishers (Fig. 27), Dowden, Hutchinson and Ross (Fig. 28), VSP (Fig. 29), Applied Science Publishers (Fig. 30), Plenum Press (Fig.31), Blackwell Publishers (Fig. 20, ya citada en la pag. 43), y Jobn Wiley and Sons (Fig.14, ya citada en la pag. 41).

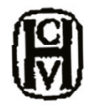

\section{Carl Hanser Verlag München 1970}

Figura 25

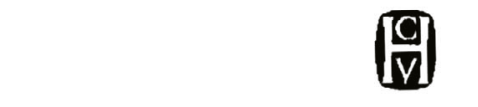

CARL HANSER VERLAG MÜNCHEN 1963

Figura 26

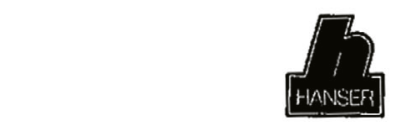

Hanser Publishers, Munich Vienna New York

Hanser/Gardner Publications, Inc., Cincinnati

Figura 27

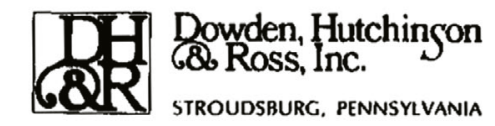

Figura 28

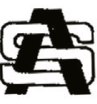

APPLIED SCIENCE PUBLISHERS LTD LONDON

Figura 30
/I/VSP/I/

Utrecht, The Netherlands, 1993

Figura 29
$\Phi$ PLENUM PRESS · NEW YORK · 1970

Figura 31 
Naturalmente, no existen tipos que pudiéramos denominar puros ya que algunos pueden utilizar diseños caligráficos y contener también algunos pequeños simbolismos como en el caso del "logo" de Springer, en el que sobre un diseño tipográfico se insertan las iniciales del fundador Julius Springer (Figs. 9-12, ya citadas en la pag. 39-40) coronadas por una pieza de ajedrez que alude al propio apellido del editor y a su afición por dicho juego; de hecho, en una variación del diseño para una filial, el único motivo existente era dicha pieza exclusivamente (Fig. 12, ya citada en la pag. 40), Thieme (Fig. 33) o Taylor and Francis (Fig. 19, ya citada en la pag. 43). Algunas otras marcas se basan en la representación de figuras que pueden ser animales -también queriendo simbolizar elementos como la energía, la fuerza o la inteligencia-, como el caso de F. J. Lebmanns Verlag (Fig. 34), o humanas, como Chapman and Hall (Fig. 32) que también posee una marca de tipo caligráfico (Fig. 35)

Georg Thieme Publishers Stuttgart 1977

Figura 33

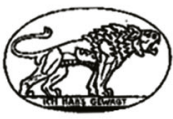

J. F. Lehmanns Verlag, München/Berlin 1942

Figura 34

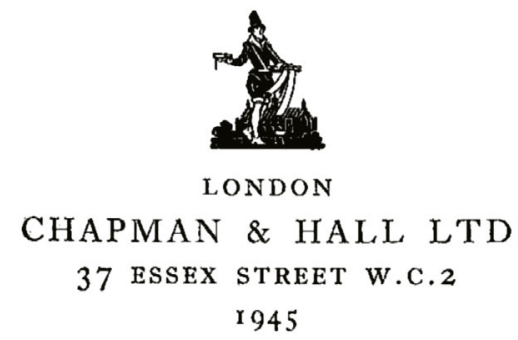

Figura 32

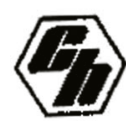

CHAPMAN AND HALL

LONDON

Figura 35 
o Edward Arnold (Fig. 36), o bien la representación de objetos inanimados que simbolizan el nombre de la editorial como Les Editions de l'Amphora (Fig. 37), o la de Temple Press (Fig.38). Además, un motivo muy recurrente es el libro, el cual puede observarse en sus más variadas formas: aislado como en Wolters Kluwer (Fig.23, ya citada en la pag. 45) o Marcel Dekker (Fig.39).

O también formando parte de otro conjunto, véase el de D. Van Nostrand Company (Fig. 40), o constituyendo un atributo que es llevado por alguna figura humana como en la marca de Chapman and Hall (Fig. 32, citada en la pag. 47) en la que un gigante se pasea entre las casas de una ciudad portando un libro en una mano.

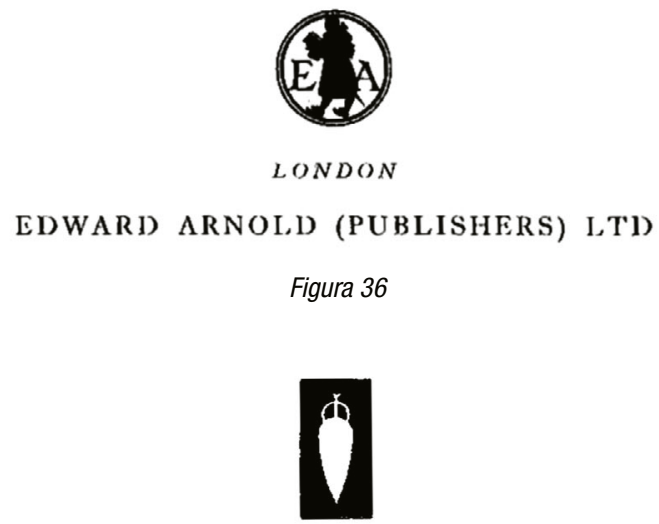

LES EDITIONS AMPHORA

119, avenue Parmentior

PARIS (XI')

Figura 37

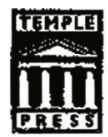

TEMPLE PRESS BOOKS

LONDON 1965

Figura 38 


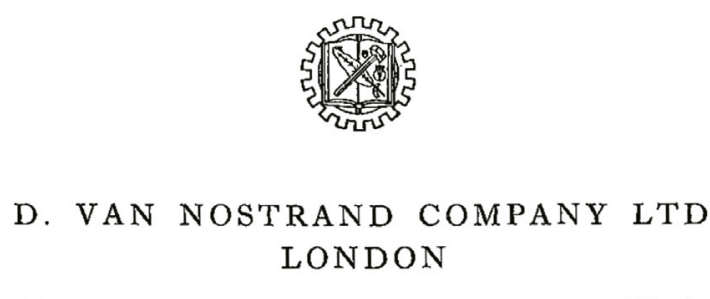

TORONTO

NEW YORK

PRINCETON, NEW JERSEY

Figura 40

Con todo lo anterior podríamos establecer la categorización siguiente:
a) Marcas basadas en objetos
b) Marcas simbólico-tipográficas
c) Marcas caligráficas

Si bien es posible realizar esta división artificial, hemos de decir que su misión es la misma en todos los casos, como veremos a continuación.

Uno de los caracteres claves de la venta actual es la publicidad y el diseño del artículo o producto a anunciar. Los libros no son ajenos a este principio comercial y un temprano ejemplo de cómo es posible la venta mediante el reconocimiento de una marca la proporciona la editorial Penguin con el logotipo creado por Jan Tschichold en los años $30 .{ }^{10}$ Un logotipo es básicamente una configuración realizada a base de letras o dibujos, o ambos, usada para representar a un organismo, empresa o actividad. Se trata, de alguna manera, de una "abreviatura" con impacto visual y que, además, es propia del siglo XX. ${ }^{11}$ No obstante, un antecedente importante de los logotipos puede encontrarse en la Inglaterra victoriana en los letreros de las tiendas, donde las empresas mostraban los nombres de los dueños, de los fabricantes y las firmas familiares. ${ }^{12}$ Este hecho suponía también una evolución en el concepto de representación, si lo comparamos con las abstracciones y simbolismos de las marcas tipográficas

10 R. Fawcent-Tang. (ed.), Diseño de libros contemporáneos, Barcelona: Gustavo Gili, 2004, p. 7.

11 J. Muller-Brockmann, Historia de la comunicación visual, Barcelona: Gustavo Gili, 1988.

12 M. Gordon; E. Dodd, Tipografía decorativa, Barcelona, Gustavo Gili, 1994. 
antiguas. Elementos como el color, propio de la época contemporánea, ayudan a la identificación de una marca, aunque en los casos que hemos citado el color únicamente es utilizado en la cubierta de la publicación y no en su portada.

Por otro lado, el concepto formal del libro ha variado muy poco en los últimos siglos. Podemos afirmar con Satué que existe una correspondencia simbólica entre las partes del libro y diversos elementos arquitectónicos como la portada, la cual, en mi opinión, al convertirse en la fachada del establecimiento que nos está ofreciendo el producto, debe llevar también una señalización; es decir, precisamente la marca del editor, de forma similar al cartel anunciador de los negocios comerciales del siglo XIX, y quizá también el XVIII; empresas que debían atender también a un proletariado urbano cuyo número no dejaba de crecer al igual que la propia oferta comercial, lo cual creaba la necesidad de que se distinguieran fácilmente unas de otras en aras de la competencia. La imagen de identidad vende, sin duda alguna, ${ }^{13}$ y el diseño de la imagen de identidad corporativa se ha convertido hoy día en algo fundamental.

Es necesario también tener en cuenta movimientos artísticos como el Arts and Crafts de la segunda mitad del siglo XX, el modernismo y el Art Decó, que influyeron en el diseño de libros, al igual que los experimentos constructivistas, futuristas y de la Baubaus. En efecto, estos movimientos vanguardistas empezaron a plantear alternativas "radicales" a la composición tipográfica, como las denominadas "palabras en libertad" de los futuristas de Marinetti desde principios del siglo XX; las composiciones de los dadaístas o los neoplasticistas de Van Doesburg. ${ }^{14}$ Reflejos de ello son las marcas de imprenta creadas por Morris ya a finales del siglo XIX, y como antecedentes de artista diseñador podemos citar a Durero y su conocido monograma en el ámbito de la representación caligráfica, como un eficaz "eslogan publicitario".

Por otro lado, y en relación con lo anterior, no es extraño que sea también notoria la utilización en el siglo XX de conocidos diseñadores para los logotipos y que se produzca una fuerte competencia entre ellos. Ya en los años 30, los diseñadores conectados con la Baubaus llevaron a cabo intentos de diseñar alfabetos como Schmidt, Tschichold o Renner; otros como Schwitter, teorizaban opinando en la revista Mertz que

La calidad significa simplicidad y belleza. La simplicidad significa claridad, forma unívoca y funcional del tipo, eliminación de todo argumento superfluo y de toda forma que será inútil (...). ${ }^{15}$

13 E. Satue, El diseño gráfico. De los orígenes a nuestros días, Madrid: Alianza, 1994, pp. 82-83.

14 E. Satue, El diseño de los libros del pasado, del presente y tal vez del futuro, La huella de Aldo Manucio, Madrid: FGSR, 1998. 
Ejemplos de estas ideas los tenemos en la simplicidad con que las editoriales presentan sus marcas buscando ese impacto visual y la facilidad de reconocimiento. Los logotipos se convierten así en íconos modernos que almacenamos en nuestras mentes, ya que el objeto es captado de un solo y único vistazo y ello nos puede inducir a la compra de los artículos con los que relacionamos esa imagen, la cual adquiere ante nuestra vista toda una serie de caracteres de seriedad, prestigio o confianza.

Quiero decir, para finalizar, que las marcas tipográficas, sobre todo las correspondientes al siglo XX, en mi opinión no han recibido toda la atención que merecen y que un estudio en profundidad sería muy recomendable para mostrar la gran riqueza de diseños que a lo largo del tiempo han ido desarrollando estas editoriales así como su conexión con los distintos movimientos artísticos que se han sucedido a lo largo de dicho siglo.

\section{BiBLIOGRAFÍA}

Brigs, A., "At the sign of the Ship", en Essays in the History of Publishing, London: Longman, 1974.

Brace, C., "Publishing and publishers towards an historical geography of country side writing, c. 1930-1950", en Área 33.3 (2001), pp. 287-296.

Dreyfus, J., Into Print: Selected Writings on Printing History, Typography on Book Production, London: The British Library, 1994.

Escolar Sobrino, H., Historia Universal del Libro, Madrid: Pirámide, 1993.

Fawcett-Tang (ed.), Diseño de libros contemporáneos, Barcelona: Gustavo Gili, 2004.

Gordon, M.; Dodd, E., Tipografía decorativa, Barcelona: Gustavo Gili, 1994. , La imprenta en Medina del Campo, Madrid: Sucs. De Rivadeneyra, 1895, Ed. Facsimil: Salamanca, Junta de Castilla y León, 1992.

Martínez de Sousa, J., Diccionario de bibliología y ciencias afines, Madrid: Pirámide, 1989.

Meadows, A.J., "Science publishing in the twentieth century", en Thorton and Tully's Scientific Books, libraries and Collectors, Aldershot. 2000, pp. 272-297.

Moran, J., Heraldic Influence on Early Printers'Devices, Leeds: The Elmete Press, 1978.

Muller, H., "The publishing industry and the european society of mass communication around 1900", en Internationales Archiv Sozialchichte der Deutschen Literatur, 27.1 (2002), pp. 170-197.

Muller-Brockmann, J., Historia de la comunicación visual, Barcelona: Gustavo Gili, 1988.

Pérez Pastor, C., Bibliografía madrileña o descripción de las obras impresas en Madrid, Madrid, 1891-1907. 
Sarkowsky, H., Springer-Verlag: History of a Scientific Publishing House, Berlin: Springer, 1996.

"Schorlarly publishing: books, journals, publishers, and libraries in the twentieth century" (Ed. Richard E. Abel et altri), New York: John Wiley and Sons, 2002.

Satue, E., El diseño de libros del pasado, delpresente y tal vez del futuro, La huella de Aldo Manucio, Madrid:Fundación Germán Sánchez Ruipérez, 1998. El diseño gráfico. Desde los orígenes hasta nuestros días, Madrid: Alianza, 1994.

Silvestre, L.C., Marques tipographiques ou recueil des monogrames, chiffres, enseignes, emblèmes, devises, rebus et fleurons des libraries et imprimeurs... en France: depuis l'introduction de l'imprimerie en 1470 jusqu'a la fin du seizième siècle, Bruxelles: Culture et Civilization, 1966.

Underwood, W., "On presses and press marks", en Journal of Scholarly Publishing, 31.1 (2000), pp. 136-142.

Vindel, F., Escudos y marcas de impresores y libreros en España durante los siglos XV al XIX (1485-1800), Barcelona: Orbis, 1942. 